\title{
Conservation through calibration and communication
}

\author{
B. P. Tullis \& S. L. Barfuss \\ Utah State University, USA
}

\begin{abstract}
To effectively manage a water resource, one must be able to quantify it. For appropriately constructed flow measurement structures, the level of practical and technical understanding of the operations and maintenance personnel often controls the difference between accurate and inaccurate flow measurement. In addition to accurate discharge data, another key element to effective water resource management is the availability of the data in real time. As part of a case study, the flow measurement structures associated with a local water distribution system were inspected, evaluated, and corrective actions recommended, where appropriate, to improve flow measurement accuracy. Telemetry communications systems were also installed making the data available real time via the Internet. This paper presents the results of this case study, including the findings, corrective actions, and training provided.
\end{abstract}

Keywords: flow measurement, telemetry, flumes, calibration, real-time data.

\section{Introduction}

As the demand for water continues to increase, particularly in the more arid regions of the world, responsible water resource management and equitable distribution become more and more critical, at local, national, and international levels. To effectively manage any resource, including water, the ability to quantify that resource, accurately distribute it, and evaluate impact or productivity is essential. For water distribution systems of any size, the first fundamental principle in effective water allocation is accurate flow measurement.

Many water distribution systems have the infrastructure in place to measure flow rates in canals and rivers. In open channel flow applications, weir or flume 
calibrations can often be inaccurate due to an incorrect staff gage datum reference, dimensional or elevation errors associated with fabrication or installation, the effective shorting of a weir height due to sedimentation, submergence, or other maintenance issues.

With most flow measurement systems, a minimum level of maintenance is often required to insure an acceptable level of accuracy. Another potential problem arises if those who perform the periodic field calibrations do not fully understand the operational procedures/principles for the measurement equipment or when they do not have access to or the ability to update the head-discharge relationships in the data logging system. Over time, minor errors in flow measurement can add up to very large volumes of inappropriately allocated water.

The potential for flow-measurement data to impact the water resource management decision making process increases when the data are available realtime. For remote measurement structures, this typically requires a telemetry system linking the data recorder to a computer. Telemetry also represents another system component that may require periodic maintenance, troubleshooting, and operations and maintenance personnel with a minimum level of system knowledge and fundamentals.

The specific objectives of this study focused on flow measurement accuracy as it applies to water resource management. Specific topics that were investigated included: field inspection of open channel flow measurement structures, identifying any structure irregularities [i.e., recommended vs. actual dimensions, improperly located staff gages (station or elevation), sedimentation deposits, poor approach flow conditions, etc.], advising the responsible party on possible ways to remedy the deficiencies, providing an accurate field calibration where possible, and educating water managers on maintenance procedures in an effort to avoid future problems. This flow measurement evaluation process was applied to a water distribution system in Northern Utah (USA) and the results are presented as a case study.

With an accurate flow measurement/distribution system in place, additional information such as local soil-moisture content and evapo-transpiration rates can further assist in determining appropriate water application rates and frequencies. The process of correlating water demand, supply, and productivity (total crop yield, crop yield per unit of applied water, crop quality, and others) are essential for maximizing our water resource potential. These issues, though related to the topic of this paper, are beyond the scope of this study.

\section{Background}

The State of Utah is located in the Western part of the United States, has a semiarid climate, and is the $49^{\text {th }}$ driest State out of 50, receiving on average 13 inches of rainfall per annum. Over the last 150 years, approximately 6,000 dams/reservoir projects have been completed around the State to capture and store the spring runoff (snow melt), primarily for municipal and irrigational use. While the water resource management in Utah has allowed the desert to 
"bloom," the resulting population growth has placed increasing strains on Utah's semi-arid water climate.

The Summit Creek distribution system, located in Northern Utah, provides irrigation water to area farmers, the distribution of which is controlled, in part, by four open channel flow measurement structures. Two factors lead to the selection of Summit Creek as the case-study site for this project; its close proximity to Utah State University $(\sim 12 \mathrm{~km})$ and a River Commissioner with an expressed interested in project participation.

\section{Data collection}

In an effort to verify and improve, where possible, the accuracy of the open channel flow measurement structures in the Summit Creek distribution system, this project was undertaken with the following objectives:

1. Inspect all flow measurement structures for:

a. Dimensional accuracy and levelness of structure

b. Staff gage location (station and elevation)

c. Approach flow conditions

d. General maintenance issues

e. General performance issues

2. Provide recommendations for adjustments/improvements based on inspection results.

3. Conduct a field calibration using current metering techniques

4. Inform the River Commissioner of all findings and results and provide operation and maintenance training where appropriate.

5. Install a telemetry system at appropriate flow measurement structures to facilitate real-time data access via a State of Utah Division of Water Rights webpage.

To apply standard rating curves or discharge coefficients for Parshall and Cutthroat flume designs, the crest and inlet of the flume must be level. According to Genovez et al. [1], out-of-level flumes, laterally and longitudinally, can result in flow measurement errors of up to $28 \%$. Elevations were measured at the inlet, outlet, crest, and staff gage location using a SOKKIA surveying level and rod. The published head-discharge or rating curve data for Parshall and Cutthroat flumes are size-specific, based on throat width (i.e., 1-ft, 2-ft, etc.), and can be found in many flow measurement handbooks (e.g. [2]).

For the published head-discharge data to be applicable to a particular flume, the flume must be built to the standardized dimensional specifications $([2,3])$. Additionally, the empirical relationships for predicting flume discharge use the upstream flow depth, measured relative to the crest and at a prescribed location, as the independent variable. If the upstream staff gage is incorrectly positioned (station or elevation), predictive error results. The structural dimensions of each flow measurement devise were compared against the standard dimensions published in [3]. 


\subsection{Field calibration}

Field calibrations were conducted as follows: a calibration cross section was selected, typically just downstream of the flume inlet (or upstream of the weir) where flow conditions were well behaved (i.e. no significant local flow accelerations, turbulence, or flow separation regions). A measuring tape was placed across the calibration section, oriented perpendicularly to the flume centreline. The calibration cross section was divided up into subsections such that no more than $10 \%$ of the total discharge passes through any subsection. Flow depths were measured at each subsection. The flow velocity for each subsection was measured with a velocity probe located at $6 / 10^{\text {ths }}$ of the flow depth from the water surface. The total discharge was calculated by summing the product of the cross-sectional flow area and the measured flow velocity of each subsection, as shown in eqn (1).

$$
Q=\sum_{i=1}^{n} Q_{i}=\sum_{i=1}^{n} V_{i} y_{i} w_{i}
$$

In eqn (1), $Q$ is the total discharge, $Q_{i}$ is the subsection discharge, $V_{i}$ is the subsection velocity, $y_{i}$ is the subsection flow depth, $w_{i}$ is the subsection width, and $n$ is the number of subsections in the cross-section. For each discharge condition, the data collection or velocity traverse was repeated a second time to verify accuracy. If discrepancies were found between the two velocity traverses, a third velocity traverse was conducted. Based on the irrigation schedules and seasonal flow rate variations in the canals, multiple calibration trips to each flow measurement structure were typically required to obtain a reasonable number and range of discharge conditions for the flow measurement structure's headdischarge calibration.

Three different current meters were used for calibration work. A Pigmy propeller meter was used for low velocity applications; an AA Price propeller meter was used for higher velocity applications. A Marsh-McBirney Flo-Mate magnetic current meter was also used for high and low velocity applications. Velocity range and meter availability were factors in selecting a current meter for a particular calibration. Once a current meter was selected for a particular flow measurement structure, however, the same current meter was used for all calibration work on that structure.

Table 1: $\quad$ Summary of summit creek flow measurement structures inspected.

\begin{tabular}{|c|l|l|}
\hline No. & \multicolumn{1}{|c|}{ Size } & \multicolumn{1}{|c|}{ Type } \\
\hline 1. & $0.91-\mathrm{m}(3-\mathrm{ft})$ & $\begin{array}{l}\text { Parshall flume (pre-fabricated fiberglass set } \\
\text { in concrete) }\end{array}$ \\
\hline 2. & $0.91-\mathrm{m}(3-\mathrm{ft})$ & $\begin{array}{l}\text { Parshall flume (pre-fabricated fiberglass set } \\
\text { in concrete) }\end{array}$ \\
\hline 3 & $2.45-\mathrm{m}(8-\mathrm{ft})$ & Parshall flume (concrete) \\
\hline 4. & $1.83-\mathrm{m}(6-\mathrm{ft})$ & Cutthroat flume (concrete) \\
\hline
\end{tabular}




\subsection{Inspected flow-measurement structures}

The four Summit Creek distribution system flow measurement structures inspected and calibrated are listed in Table 1 by size and type. Three are Parshall flumes and one a Cutthroat flume. Schematics of the Parshall and Cutthroat flumes are shown in Figures 1 and 2, respectively. The Parshall flume dimensions for specific throat widths are listed in Table 2.

Table 2: $\quad$ Parshall flume dimensions as identified in Figure 1 (ES units).

\begin{tabular}{|c|c|c|c|c|c|c|c|c|c|c|c|c|c|c|c|c|c|c|c|c|c|c|c|c|c|c|c|}
\hline \multirow{2}{*}{\multicolumn{2}{|c|}{$w$}} & \multirow{2}{*}{\multicolumn{2}{|c|}{ A }} & \multirow{2}{*}{\multicolumn{2}{|c|}{$\frac{2}{3} A$}} & \multirow{2}{*}{\multicolumn{2}{|c|}{ B }} & \multirow{2}{*}{\multicolumn{2}{|c|}{ 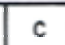 }} & & \multirow{2}{*}{\multicolumn{2}{|c|}{ E }} & & \multirow{2}{*}{\multicolumn{2}{|c|}{ G }} & \multirow{2}{*}{\multicolumn{2}{|c|}{ M }} & \multirow{2}{*}{\multicolumn{2}{|c|}{$M$}} & \multirow{2}{*}{\multicolumn{2}{|c|}{$\mathbf{P}$}} & & \multicolumn{2}{|c|}{ FREE - FLOW CAPACITY } \\
\hline & & & & & & & & & & & & & & & & & & & & & & & & & & MINIMUM & MAXIMUN \\
\hline $\mathrm{FT}$. & IN. & $\mathrm{FT}$. & IN. & FT. & IN. & FT. & IN. & FT. & & $F \mathrm{~T}$ & IN. & $F \mathrm{~T}$ & in. & $F \mathrm{~T}$ & IN. & $F \mathrm{~T}$ & in. & $F \mathrm{~T}$. & IN. & $F \mathrm{~T}$. & IN. & & IN. & $F \mathrm{~T}$ & IN. & CFS & CFS \\
\hline 0 & 6 & 2 & $\frac{7}{16}$ & 1 & $4 \frac{3}{6}$ & 2 & 0 & 1 & $3 \frac{1}{2}$ & 1 & $3 \frac{5}{8}$ & 2 & 0 & 1 & $\overline{0}$ & 2 & 0 & 1 & 0 & 0 & $4 \frac{1}{2}$ & 2 & $11 \frac{1}{2}$ & I & 4 & .05 & 3.9 \\
\hline & 9 & 2 & $10 \frac{5}{6}$ & 1 & $11 \frac{1}{6}$ & 2 & 10 & 1 & 3 & 1 & $10 ?$ & 2 & 6 & 1 & 0 & 1 & 6 & I & 0 & & $4 \frac{1}{2}$ & 3 & $6 \frac{1}{2}$ & I & 4 & .09 & 8.9 \\
\hline 1 & 0 & 4 & 6 & 3 & 0 & 4 & $4 \frac{7}{6}$ & 2 & 0 & 2 & $9 \frac{1}{4}$ & 3 & 0 & 2 & 0 & 3 & 0 & 1 & 3 & & 9 & 4 & $10 \frac{3}{4}$ & 1 & 8 & 五 & 16.1 \\
\hline I & 6 & 4 & 9 & 3 & 2 & 4 & $7 \frac{7}{6}$ & 2 & 6 & 3 & $4 \frac{3}{3}$ & 3 & 0 & 2 & 0 & 3 & 0 & 1 & 3 & & 9 & 5 & 6 & 1 & 8 & .15 & 24.6 \\
\hline 2 & 0 & 5 & 0 & 3 & 4 & 4 & $0 \frac{7}{6}$ & 3 & 0 & 3 & $1 \frac{1}{2}$ & 3 & 0 & 2 & 0 & 3 & 0 & 1 & 3 & & 9 & 6 & I & 1 & 8 & .4 & 33.1 \\
\hline 3 & 0 & 5 & 6 & 3 & 8 & 5 & $4 \frac{3}{4}$ & 4 & 0 & 5 & $1 \frac{7}{8}$ & 3 & 0 & 2 & 0 & 3 & 0 & 1 & 3 & & 9 & 7 & $3 \frac{1}{2}$ & 1 & 8 & .61 & 50.4 \\
\hline 4 & 0 & 6 & 0 & 4 & 0 & 5 & $10 \frac{5}{6}$ & 5 & 0 & 6 & $4 \frac{1}{4}$ & 3 & 0 & 2 & 0 & 3 & 0 & 1 & 6 & & 9 & 8 & $10 \frac{3}{4}$ & 2 & 0 & 1.3 & 67.9 \\
\hline 5 & 0 & 6 & 6 & 4 & 4 & 6 & $4 \frac{1}{2}$ & 6 & 0 & 7. & $6 \frac{5}{3}$ & 3 & 0 & 2 & 0 & 3 & 0 & I & 6 & & 9 & 10 & $1 \frac{1}{4}$ & 2 & 0 & 1.6 & 85.6 \\
\hline 6 & 0 & 7 & 0 & 4 & 8 & 6 & $10 \frac{5}{6}$ & 7 & 0 & 8 & 9 & 3 & 0 & 2 & 0 & 3 & 0 & 1 & 6 & & 9 & 11 & $3 \frac{1}{2}$ & 2 & 0 & 2.6 & 103.5 \\
\hline 1 & 0 & 7 & 6 & 5 & 0 & 7 & $4 \frac{1}{4}$ & 8 & 0 & 9 & 13 & 3 & 0 & 2 & 0 & 3 & 0 & I & 6 & & 9 & 12 & 6 & 2 & 0 & 3.0 & 121.4 \\
\hline 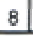 & 0 & 8 & 0 & 5 & 4 & 7 & $0 \frac{1}{6}$ & 9 & 0 & 11 & & 3 & 0 & 2 & 0 & 3 & 0 & 1 & 6 & & 9 & 13 & $8 \frac{1}{4}$ & 2 & 0 & 3.5 & 139.5 \\
\hline
\end{tabular}

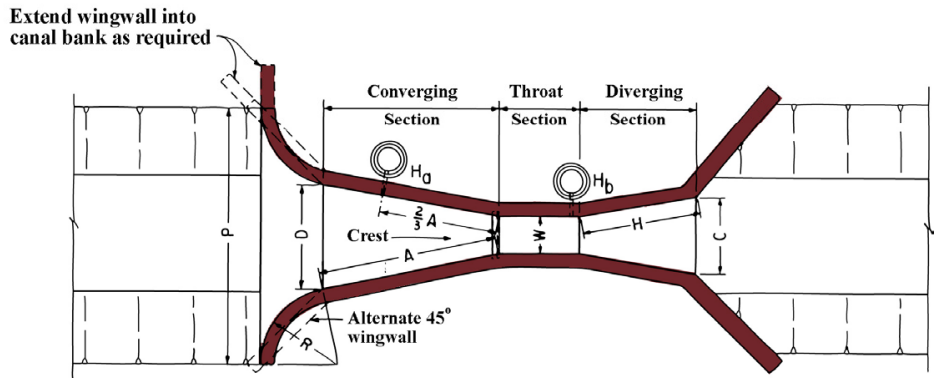

PLAN



PROFILE

Figure 1: Parshall flume schematic. 

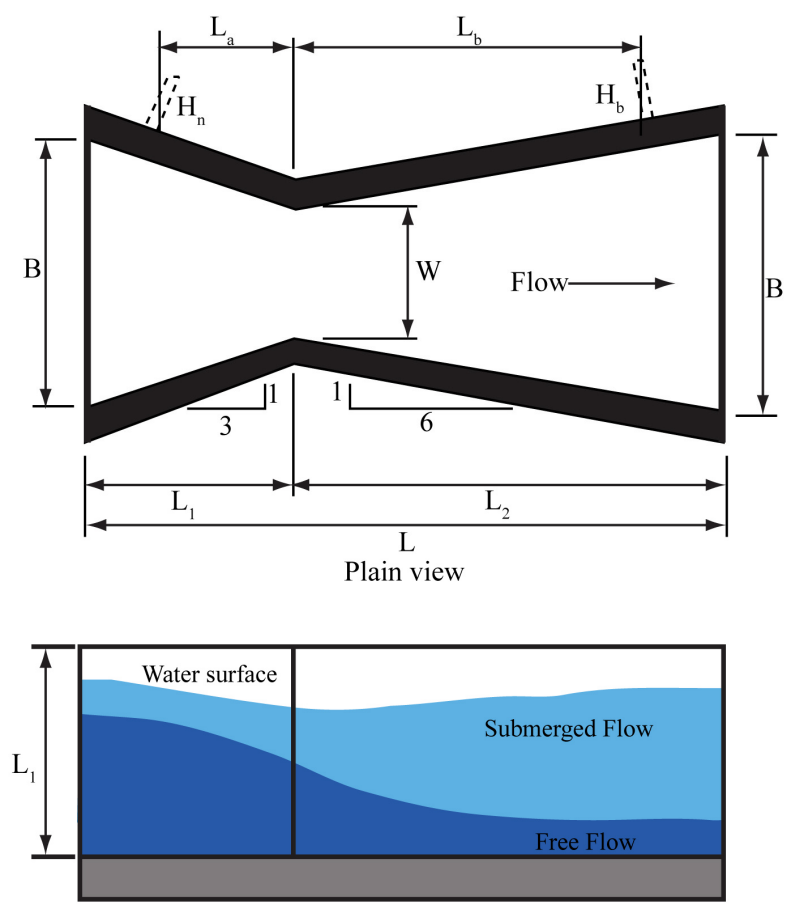

Elevation view

$$
\begin{array}{ll}
\mathrm{B}=\mathrm{W}+2 \mathrm{~L}_{1} / 3=\mathrm{W}+\mathrm{L}_{2} / 3 \\
\mathrm{~L}_{2}=2 \mathrm{~L} / 9 & \mathrm{~L}_{\mathrm{b}}=5 \mathrm{~L} / 9
\end{array}
$$

Figure 2: $\quad$ Cutthroat flume schematic.

\section{Summary of findings}

\subsection{General problems and corrective actions}

The most common problem that required a corrective action was a staff-gage zero that did not correspond to the flume crest elevation. For each case, a staff gage adjustment $(\Delta Z)$ was determined using surveying equipment to determine the average crest elevation (three survey points) and the invert elevation at the staff gage location. With $\Delta Z$, determined, a custom head-discharge relationship can be created by adding $\Delta Z$ to the flow depth term or the staff can be adjusted to by $\Delta Z$. The latter is recommended because then the only information required to determine the discharge is the staff gage reading and the standard head-discharge tables or equations.

\subsection{Specific findings}

Structure \#1 was out-of-level and had a staff gage $\Delta Z$ offset of $\sim 95 \mathrm{~mm}$. The uncorrected flow depth staff gage data, however, predicted a head-discharge 
curve consistent with the theoretical head-discharge curve (using the standard 3$\mathrm{ft}$ Parshall flume head-discharge relationship). The discharge predictive error associated with the corrected flow depth data (adjusted to the crest reference elevation) was significantly higher than the uncorrected data. Apparently, the staff gage elevation had been altered to account for flume geometry problems such as being out of level. Consequently, no corrective action was required.

Structure \#2 was also out of level and $\Delta Z \sim 6 \mathrm{~mm}$. Adjusting the staff gage reading by $\Delta Z$ decreased the average discharge predictive error from $\sim 6 \%$ to $3.5 \%$. Some of the dimensions of Structure \#3 were inconsistent with standard design and $\Delta Z \sim 29 \mathrm{~mm}$. Adjusting the staff gage decreased the average discharge predictive error from $40 \%$ to $3.5 \%$. The maximum errors associated with the pre- and post-correction data were $66 \%$ and $8 \%$, respectively.

Structure \#4, referred to a "three creeks," presented the most interesting challenge. A two-creek confluence was located just upstream of the flume. Immediately downstream of the flume was the confluence with the third creek and a diversion structure. The flume tailwater, influenced by the diversion structure, created a $\sim 100 \%$ flume submergence condition, as shown in Figure 4(A). Producing a "rated section" calibration was not possible as the head-discharge relationship through the flume was non-unique due to independent variations in head and discharge caused by the downstream confluence and diversion structure. With buy-in from the River Commissioner, a decision was made to fabricate and install a sharp-crested linear weir on the downstream side of the Parshall flume. It was determined that under base-flow conditions, there was sufficient freeboard upstream of the weir to accommodate an elevated linear weir crest, capable of forming a critical section above the high tailwater. During spring runoff, the weir will be removed due to flood risk associated with high flow rates and because the momentum associated with the elevated flow rates will likely sweep out the downstream end of the Parshall flume, allowing it to function unsubmerged. A photo of the removable sharpcrested weir is shown in Figure 4(B). The linear weir will be calibrated during the 2009 irrigation season.

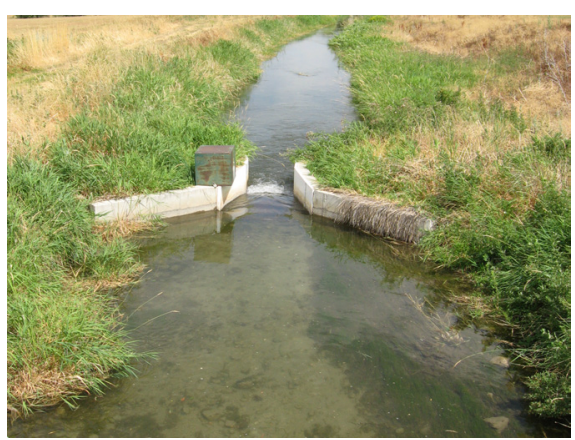

(A)

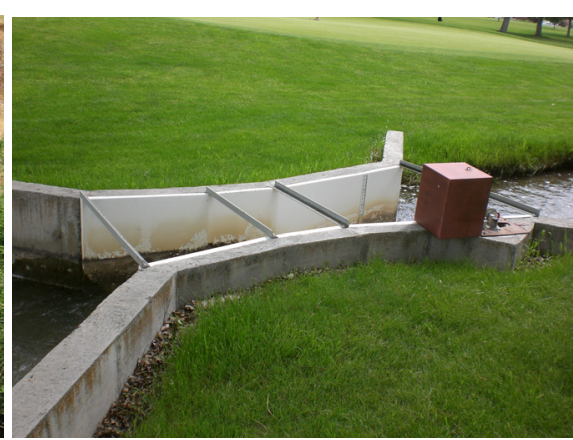

(B)

Figure 3: $\quad$ 3-ft (0.9-m) Parshall flumes, Structure \#1 (A), Structure \#2 (B). 


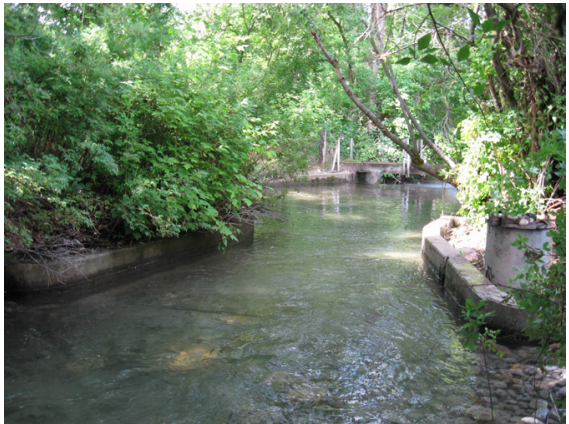

(A)

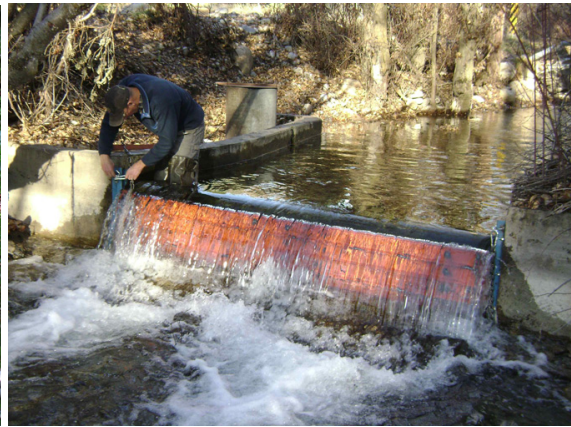

(B)

Figure 4: 8-ft (2.4-m) Parshall flume (Structure \#4), operating fully submerged (A) and with the sharp-crested linear weir installed (B). (Note: tailwater lowered for weir installation.)

\subsection{Real-time data (telemetry)}

During this study, telemetry system installations were completed at two of the four flow measurement structure locations and partial installations were started at the other two. The real-time discharge or diversion data are available via the Internet http://waterrights.utah.gov/distinfo/realtime_info.asp, under Bear River Overview, Summit Creek.

\subsection{Training}

The findings of this study were shared at the annual meeting of the Summit Creek Distribution System and specifically with the River Commissioner. The recommended head-discharge relationships were reviewed, the specific findings and corrective actions taken for each structure were reviewed, the how to access the real-time telemetry flow rate data on the Internet.

\section{Conclusions}

Four flow measurement structures (3 Parshall flumes, 1 Cutthroat flume) in the Summit Creek Distribution System were inspected and field calibrated. With the exception of Structure \#4, which was operating fully submerged due to a high tailwater created by a diversion structure located immediately downstream, the only problems found with the flow measurement structures were flumes slightly out-of-level and the staff gages had incorrect crest references.

When someone has the training and motivation, the incorrect staff gage location is a problem that is easily detected (provided that a survey level and rod are available) and corrected. In one case (Structure \#3), the maximum error between the discharge predicted using the "as is" staff gage reading with the standard calibration equation and the field calibrated discharge was reduced from $67 \%$ to $8 \%$. Minor errors in the operation and/or maintenance of a flow 
measurement structure can have a significant impact on the accuracy of the discharge data generated by that device. Routine inspection and maintenance by personnel who understand the practical and engineering side of open channel flow measurement is required to reduce the risk of easily identified and corrected errors having a significant impact for flow measurement accuracy.

\section{Acknowledgments}

Funding for this study was provided by the US Geological Survey and the State of Utah.

\section{References}

[1] Genovez, A., Abt, S., Florentin, B., Garton, A., Correction for settlement of parshall flume, Journal of Irrigation and Drainage Engineering, 119(6), pp. 1081-1091, 1993.

[2] U.S. Bureau of Reclamation (USBR), Water Measurement Manual (Chapter 8), US. Dept. of the Interior, Bureau of Reclamation, $3^{\text {rd }}$ Ed., 2001.

[3] State of Utah, Utah Water Measurement Pocket Reference, Utah Association of Conservation Districts, Salt Lake City, Utah, pp. 10-19, 2000. 